\title{
A CONSTRUCÃO DE SI MESMA: A PRESENCA DA FIGURA DE KIKI DE MONTPARNASSE NO CENÁRIO VANGUARDISTA
}

\begin{abstract}
THE CONSTRUCTION OF HERSELF: THE PRESENCE OF THE FIGURE OF KIKI OF MONTPARNASSE IN THE VANGUARDIST SCENARIO
\end{abstract}

Anelise Valls Alvarez ${ }^{1}$ 


\section{Resumo}

O escopo deste artigo consiste em traçar alguns pontos da construção da figura de Alice Prin - mais conhecida como Kiki de Montparnasse - em relação os reconhecidos artistas homens modernistas durante o período do entre-guerras (1920-1930), - bem como a construção-invenção de si mesma observada no conjunto da produção artística de Kiki. Neste sentido, buscamos por um lado, compreender a ambiência deste mundo que a retratou e, por outro, para efeito de contraposição a este contexto, nos detemos na participação feminina peculiar de Kiki e os escritos de seu diário.

Palavras-chave: participação feminina; Kiki de Montparnasse; Modernismo; cenário vanguardista.

\section{Abstract}

The scope of this article is to trace some points of the construction of the figure of Alice Prin - better known as Kiki of Montparnasse - in relation to the well-known modernist male artists during the interwar period (1920-1930), and also the invention of herself observed in the whole of Kiki's artistic production. In this sense, we seek, on the one hand, to understand the ambience of this world that portrayed her and, on the other hand, to counteract this context, we dwell on the peculiar feminine participation of Kiki and the writings of her diary.

Keywords: Female Participation; Kiki de Montparnasse; Modernism; Avant-garde Scene. 


\section{Introdução}

As abundantes manifestações artísticas dos anos de 1920-1930 são normalmente ancoradas na figura de uma liderança masculina de vanguarda. A fim de destacar e rastrear estruturas e tramas engendradas a partir de presenças femininas, nosso foco é redimensionar a presença de Kiki de Montparnasse, pseudônimo de Alice Prin. Reconhecida, à época, como "musa" de pintores, escultores, cineastas e colecionistas, a figura social de Kiki, assim apelidada pelos amigos, também pode ser vista como uma invenção de si mesma, isso porque ela desvia de uma série de padrões e preceitos previstos para seu tempo e lugar historicamente.

É possível identificar o cenário parisiense como um local contraditório para mulheres no início do século XX, sendo ao mesmo tempo acolhedor e proibitivo, excitante e perigoso. Alguns historiadores articularam as várias maneiras nas quais as mulheres tentaram e eventualmente tiveram sucesso na inserção ao mundo dominadamente masculino ${ }^{1}$. Eles focaram em métodos de empoderamento político para mulheres na esfera pública bem como nos problemas de representação cultural e agência, e examinaram casos de figuras femininas do século XIX como prova que elas eram uma parte vibrante da vida pública². Assinalamos o estudo de Mary Louise Roberts (1994) sobre as mulheres francesas como agentes públicas no século XIX e início do século XX. A autora explora a nova mulher do fin de siècle e a mulher moderna do pós-guerra, argumentando a favor de uma abordagem mais complexa que dê conta da interpretação entre mulheres e a esfera pública. Neste sentido, essas novas mulheres e, mais particularmente aquelas envolvidas com a imprensa e o palco, usaram desses meios performativos para experimentar com seus diferentes "eus" públicos e conteúdos em que o "poder disruptivo de performance tinha tudo a ver com um momento histórico específico" como condição material da indústria cultural de massa "agora existente para que esse tipo de mudança ocorresse e desse lugar a uma escala considerável" (ROBERTS, 1994, p. 248)3. Em estruturas sociais ainda dominadas pelos homens, localizar devidamente o lugar de mulheres no âmbito da História da arte é imperativo ${ }^{4}$. Deslocar as figuras femininas das paredes de museus e galerias e compreender o tema feminino como central é burlar a perspectiva prevalecente e reivindicar seus lugares apropriados e legítimos (GROSENICK, 2003, p.15).

$\mathrm{Se}$, via de regra, Kiki é associada ou convertida em meramente musa e modelo, ou um mero objeto de ars imitatio, o fato é que sua presença não era calada, sua postura não era de um peão ou joguete que apenas contribuiu à tarefa de posar para artistas. Sua atividade era de um trabalho físico, mental, e ainda que não fosse da de uma estátua quieta, foi silenciada. Ela não era uma abstração, mas sim a um indivíduo,

\footnotetext{
1 Ver, por exemplo, Tamar Garb em sua obra "Sisters of the Brush: Women's Artistic Culture in Late Nineteenth-Century Paris". New Haven: Yale Press, 1994. Ou ver Sheri Benstock no livro Women of the Left Bank: Paris, 1900- 1940. Londres: Virago, 1987.

2 Citamos como exemplos os nomes de Susan Dalton, Engendering the Republic of Letters: Reconnecting Public and Private Spheres in Eighteenth-Century Europe. Montreal-Kingston: McGill-Queen's University Press, 2003. Sobre o final do século XIX e início do século XX, ver: ROBERTS, Louise. Disruptive Acts, and Civilization without Sexes: Reconstructing Gender in Postwar France, 1917-1927. Chicago: Universidade de Chicago Press, 1994.

3 Sobre performance e individualidade, indicamos a leitura de "Gender Trouble: Feminism and the Subversion of Identity" da autora Judith Butler.

4 As comentaristas feministas traçaram cuidadosamente as poderosos imagens culturais desta "nova mulher", que se tornou uma caricatura em revistas e jornais na Grã-Bretanha, América e França. Em fóruns como Yellow Book, Puck e La Plume. Essa nova mulher se dedicou a atividades não convencionais -ela bebe, fuma e lê livros - e muitas vezes foi retratada como anormalmente masculina, sexualmente corrupta e moralmente perigosa. Retratos como esses eram muitas vezes críticos e condescendentes e, como Elliott argumentou, a maioria foi tirada de categorias de mulheres, como atrizes, prostitutas e lésbicas, cuja própria existência desafiava os ideais femininos da classe média da esposa e da mãe dependentes. Estudos da nova mulher incluem Bridget Elliott, "New and Not so 'New Women' on the London Stage: Aubrey Beardsley's Yellow Book Images of Mrs. Patrick Campbell and Réjane". Victorian Studies, 1987, p.33-57; Elaine Showalter, Sexual Anarchy: Gender and Culture at the Fin de Siècle, New York: Penguin Books, 1990.
} 
que tinha voz, que articulava e discutia suas ideias, expressava e impunha vontades. O episódio no qual visita Tsuguhsru Foujita em seu ateliê é ilustrativo: ao invés de pousar para ele, ela fez seu retrato.

Então pediu o dinheiro da pose e foi-se embora triunfalmente, com seus croquis debaixo do braço. Três minutos depois, vendeu-o a um rico colecionador americano, no café Le Dôme. Fu-fu ficou sem entender qual dos dois era o artista (MOLLGAARD, 1990, p. 32).

Kiki foi uma mulher que, aparentemente, servia de modelo para que o destaque dos artistas homens fosse consumido, mas cuja atuação, ideias e posicionamentos serviram, em realidade, como um motor para a revolução modernista e conquista de espaço social para as mulheres. De carne e osso, real, com uma história, Kiki inclusive narrou suas memórias, impressões e experiências em um diário que permanece sem edição em português.

A propósito, a produção textual em língua portuguesa sobre Alice Prin é demasiada escassa, o que mantém o caráter inédito de referências e produções que pautem o coração do Modernismo do início do século XX examinando tal personagem que vivia imersa na arte das vanguardas.

\section{Kiki e a invenção de si mesma}

Kiki emerge no núcleo de Montparnasse - sede social e cultural das principais vertentes artísticas da época - e sabe imprimir intensidade à sua existência e afigura verdadeiras imagens emblemáticas documentadas por diversas ocasiões. A obra "O violino de Ingres" (1924) - fotografia de Man Ray, serve como um exemplo célebre entre as imagens de Kiki de Montparnasse propagadas: na foto observamos Kiki nua, posando de costas para a câmera, com um turbante na cabeça e aberturas de violino desenhadas na altura da lombar. Entretanto, a partir deste mesmo exemplo difundido e incorporado na história da arte tradicional, é admissível identificar uma série de lacunas que podem possuir significados complexos dentro deste mesmo contexto ou área do conhecimento.

Kiki presenciou e protagonizou o processo de renovação artística de Paris durante o período de entreguerras; frequentava a casa de André Breton, a de Gertrude Stein, a Galerie Surréaliste de la rue Jacques Callot, La Ruche, um aglomerado de artistas na rue de Vaugirard.

C'est la grande époque des dadaïstes, des cubistes, des surréalistes! Jean Cocteau, Tristan Tzara, créateur de Dada, Man Ray, Crevel, Prévert, Desnos, Picabia, Picasso, Rigault, Chadourne, Vildrac, Dessaignes, Max Ernst, Aragon, ils sont tous là... et a'utres, aussi importants et dont le nom m'échappe maintenant ${ }^{5}$ (KIKI, 2003, p. 233).

Em quase duas décadas como modelo, Kiki pousou para um grupo formado quase que exclusivamente por artistas homens: Chaïm Soutine, Maurice Utrillo, Modigliani, Francis Picabia, Fujita Tsuguji, Jean Cocteau, Alexander Calder, Per Krohg, Hermine 
David (uma das raras artistas mulheres do círculo), Pablo Gargallo, Toño Salazar, Moïse Kisling, Man Ray, entre outros.

Aos vinte e oito anos escreveu um diário e em suas memórias os descreve como "meninos grandes e crédulos" (KIKI, 2003, p. 233). O olhar de Kiki, ao contrário do que normalmente possa se associar, não era de uma entusiasta apenas ou de uma mera groupie; seu olhar era de uma observadora atenta, inteligente, perspicaz, que foi capaz de afirmar muito antes da crítica e da história cultural: "aparte de alguns verdadeiramente convencidos do que faziam, como Desnos, Aragon, Man Ray, Prévertt e alguns outros, os demais me pareciam uns amargurados"6.

Testemunhamos seus pontos de vista em seu diário Kiki's memoirs, publicado em 1929. Nele, ela conta suas histórias pessoais, momentos de ânsias e liberdade, episódios íntimos e desejos, e também narra momentos dos artistas com os quais passou boa parte de sua vida. "[...] moi je vis! Il faut que je vive! Au fait pourquoi? l'existence est-belle si agréable? Ce serait si vite fait et quel repôs ensuite!"7 (KIKI, 2003, p. 289).

Nas entrelinhas de suas memórias, podemos apreender um mundo sob a penúria econômica, visões sociais complexas em um campo de abertura e fechamento para novos discursos e propostas em um tempo que se acreditava esgotado. Outros tantos episódios de intimidade e os pontos de vista pessoais de Kiki de Montparnasse podem ser testemunhados em seu diário Kiki's memoirs, publicado em 1929.

$\mathrm{Au}$ milieu de toutes mes orgies, de mes nuits de folie, c'est la seule chose que je n'ai jamais salie, l'amour! Je suis restée la fille très sentimentale et pleine d'affection que j'ai du comprimer toite ma jaunesse! ${ }^{8}$ (KIKI, 2003, p. 230).

A autora Irene Gammel (1999) defende que a maioria dos diários sexuais femininos - esquecidos ou best-sellers - funcionou muito mais do que simples confissões: eles usaram das tradicionais confissões para dar voz a críticas contra as normas sexuais e formas tradicionais da autorrepresentação sexual feminina. Especificamente o diário de Kiki, segundo a autora, ilustra as convenções ao redor da auto-representação sexual feminina e tem uma recepção popular notória. "O livro foi entusiasticamente abraçado pela impressa masculina" (GAMMEL, 1999, p. 50. A tradução inglesa teve três introduções, todas escritas por homens, que ao invés de enaltecer o texto de Kiki, legitimavam o corpo feminino por detrás do texto. Vale lembrar que Hemingway afirma na introdução que faz ao diário, que "Kiki agora parece um monumento de si mesma e da era de Montparnasse" (KLÜVER;MARTIN, 1980, p. 56); já o tradutor inglês havia dito que o problema não era traduzir o texto de Kiki, mas traduzir Kiki e, finalmente, o editor reclamou propriedade do diário ao afirmar que foi por meio de sua sugestão e incentivo insistente que Kiki o escreveu. O ponto da autora consiste em

\footnotetext{
6 Em 1929 - ano que Kiki foi eleita Rainha de Montparnasse - foi publicado seu diário Kiki: Souvenirs com lançamento e sessão de autógrafos na Falstaff, seguido de uma coquetel no bar de Coupole. (Vale registrar que os primeiros capítulos das memórias de Kiki foram publicados em 15 de abril de 1929 , no ${ }^{0} 3$ da revista Paris Montparnasse, que ela financiava como já dito anteriormente.) O livro Kiki: Souvenirs é editado por Broca em julho de 1929, com capa de Kisling, introdução de Foujita e fotografias de Man Ray, entre outros. Uma tradução em língua inglesa por Samuel Putnam (publicado por Edward TITUS e seu Black Manikin Press) com introdução de Ernest Hemingway foi lançada no ano seguinte. Bennett Cerf, editor-chefe da Random House tentou importar 300 cópias para os Estados Unidos, porém, o livro foi barrado por apresentar conteúdo considerado pornográfico na época. Em 1998 as Memórias acrescidas dos anexos da edição americana, são reeditadas por Billy Klüver \& Julie Martin, pela editora Hazan.

7 Em português: "[...] eu vivo! Eu devo viver! Por quê? A existência é tão bonita? Isso será tão rápido e então que descanso!" (tradução minha).

8 Em português: "No meio de todas as minhas orgias, minhas noites de loucura, essa é a única coisa que eu jamais corrompi,o amor! Eu permaneci uma menina muito sentimental e cheia de carinho que teve que comprimir toda minha juventude!" (tradução minha).
} 
apontar que são estes homens que selecionam a voz da Kiki para funcionar, impondo inclusive capa própria ao diário, como a voz representativa deles e de uma era conhecida pela sua significativa proliferação de direitos legais e sexuais das mulheres. Ainda que a intenção de Kiki supostamente tenha sido dar sua versão da história, como de costume permitem os diários, sua voz foi apropriada e ganhou as matizes de um símbolo sexual do século XX e seu corpo, mais que seu conteúdo, se tornou uma característica aceita de expressão cultural.

Kiki, por outro lado, pintou e expôs incentivada por seus amigos. Em 1927, apresenta sua primeira exposição na galeria Au sacré de Printemps, com vinte e quatro obras e um catálogo elaborado pelo poeta e amigo Robert Desnos, importante artista surrealista. A abertura foi considerada um êxito e quase todas as obras vendidas. Em 1929, ela recebe o convite para expor na galeria Tremois, junto a Pascin, Hermine David, Per Krohg e Touchages. Em julho de 1930, suas telas são expostas na vitrine da livraria At the Sign of the Black Manikin, na Rue Delambre, por ocasião da publicação de suas memórias. Em novembro de 1930, Kiki expõe na galeria Bernheim da rue du Faubour Saint-Honoré de París. Como cantora, sua discografia é composta por um disco dupla face lançado em julho de 1939, seu segundo e terceiro discos saem em 1940. A revista Paris-Montparnasse (fevereiro de 1929 - março de 1930) lançada e editada por Henri Broca é parcialmente financiada por Kiki.

Je commandite une revue mensuelle quis s'appelle "PARIS-MONTPARNASSE". Le rédacteur en chef, Henri Broca, m'impressionne par ses qualities étonnantes, son intelligence, son activité inouïe. À lui seul, il fait la plupart des articles, s'occupe de tout, dessine, bientôt il deviant mon amant ${ }^{9}$ (KIKI, 2003, p. 265).

Broca organiza a eleição da Rainha de Montparnasse em 30 de maio de 1929, sob a tutela da revista, daí o título de nossa protagonista francesa após vencer a eleição (CARACALLA, 2009, p.117).

\section{A construção de Kiki no cenário vanguardista}

A atmosfera de ideias fervilhantes, que articulava uma arte produzida nos centros urbanos, passível de intenso intercâmbio cultural e intelectual, teve relação especial com pontos de encontros casuais, sobretudo em ambientes de cafés, bares e cabarés parisienses.

Habermas, em um de seus estudos que envolvem revisão de gênero e esfera pública, explora a intersecção entre a mulher francesa e o âmbito social, em suas possibilidades e limitações. Ele argumenta que no final do século XVIII, os cafés e salões da Europa se tornam locais de discurso racional e discussão crítica que, devido à ênfase na razão, podia ser aberto a qualquer um (HABERMAS, 1992, p.421-461) ${ }^{10}$.

La Rotonde, Le Dôme, La Closerie des Lilas recebiam os mais variados intelectuais e artistas, locais e estrangeiros. "Maintenant, je me sens à la Rotonde comme chez

9 Em português: "Estou patrocinando uma revista mensal chamada 'PARIS-MONTPARNASSE'. 0 editor-chefe, Henri Broca, me impressiona com suas qualidades surpreendentes, sua inteligência, sua incrivel atividade. Ele sozinho faz a maioria dos artigos, cuida de tudo, desenha e logo se torna meu amante" (tradução minha).

10 Estudos críticos de Habermas incluem: CALHOUN, Craig J. (ed.). Habermas and the Public Sphere. Cambridge Mass.: MIT Press, 1992. Ver também: MAH, Harol. Phantasies of the Public Sphere: Rethinking the Habermas of Historians, in: The Journal of Modern History 72, março/2000, p.153-182. 
moi" (KIKI, 2003, p. 144). O bairro cosmopolita parisiense de Montparnasse se torna o favorito dos principais artistas da Escola de Paris.

Pendant quelque temps, nous nous réunissons entre gens Du quartier; mais ça ne dure pás! Très vite Paris apprend qu'il existe um endroit à Montparnasse où règne toujours une folle gaîté, et où l'on rencontre toutes lês jeunes gloires ${ }^{11}$ (KIKI, 2003, p. 220).

Montparnasse se tornou um dos favoritos dos principais artistas da Escola de Paris. Sobre estes lugares particulares onde Kiki de Montparnasse frequentava e convivia com a boemia artística, a obra Memoirs of Montparnasse (2007) de John Glassco, permite acompanhar registros precisos sobre a cités d'artiste, que realizava suas criações num estilo de vida pouco convencional. Lou Mollgaard em sua obra "Kiki de Montparnasse" (1990) oferece uma biografia que considero fundamental para apurar com mais detalhes o atitude de Kiki de Montparnasse, com diversos casos narrados, como por exemplo, em janeiro de 1922 quando Tristan Tzara veio se instalar no Hotel des Écoles ao lado do quarto de Kiki, ocasião que os torna muitos amigos, principalmente nos tempos que Man Ray fica fora fotografando modelos de alta-costura (KIKI, 2003, p.70).

Esta boemia artística predominantemente masculina que formava a cités d'artistes, realizava suas criações num estilo de vida pouco convencional. Paris, nesta época, "se tornou, tanto em seus caos como em sua continuidade, a cidade cosmopolita ideal, culta, tolerante, febril, ativa, radical, mas controlada (HARRISON, 1998, p. 82) Este campo de experimentação, que muda a história social da arte, inclui Montparnasse como um centro onde ocorrem as exposições de arte, onde há galerias, colecionistas, marchantes e grande circulação de envolvidos na valorização da arte. Nesta vanguardista atmosfera circula Kiki, nome que ficará famoso no bairro.

O tema da mulher transgressora na época que compreende os anos de 1920 na França, também conhecidos como années folles, criou um espaço complexo cujo horizonte se encaminhava para a possibilidade de mulheres se re-imaginarem e rearticularem-se. Com efeito, o status da criação e participação independente artisticamente era controverso: por conta de tal "status", a mulher, majoritariamente, era aceita como musa, objeto de desejo do olhar masculino, mas não como criadora, agente ativa que olha e coloca em forma o que deseja. Kiki não se conformava nestes moldes:

Ela não foi, todavia, uma pessoa passiva satisfeita em ser objeto de atenção de artistas e homens. Ela foi uma pintora por direito próprio, com um estilo naïve, mas boa o suficiente para garantir uma exposição individual em 1927. Robert Desnos escreveu o prefácio do catálogo (GLASSCO, 2007, p. 216).

Kiki não corresponde ao estereótipo feminino da "rainha do lar". Ela sai deste lugar-comum designado socialmente às mulheres e, seu comportamento antecipa o que, poucas décadas mais tarde, se tornarão reivindicações feministas pelos direitos das mulheres: liberdade sexual, liberdade do próprio corpo e liberdade de expressão.

11 Em português: "Por um tempo, nos reunimos entre as pessoas da vizinhança; mas isso não durou! Rapidamente Paris descobre que há um lugar em Montparnasse, onde há sempre uma alegria selvagem, e onde se encontram todas as jovens glórias" (tradução minha). 
Kiki, ou Alice Prin - nome de batismo, - nasceu em 1901 em Châtillon-sur-Seine, Côte d'Or, foi criada pela avó e, aos treze anos, enviada para Paris para morar com a mãe, onde deveria começar a trabalhar e reforçar os rendimentos da família miserável. Sua vida, desde cedo, tem uma série de capítulos emblemáticos ${ }^{12}$, dentre os quais, assinalamos aqui de antemão a rejeição de sua mãe ao fragá-la posando nua para um pintor amador. Independente e ousada, Kiki traz em si a postura vanguardista e contribui na desacomodação de um contexto no qual pouco a pouco a figura feminina desponta no meio dominado por homens como modelos vivos. Vale dizer que até o século XIX, eram raras as academias europeias que aceitavam que as mulheres pousassem para os artistas. Rompendo com o papel que lhe é designado socialmente como mulher e até mesmo no ambiente de vanguarda, Kiki reforça a novidade dos modelos nus femininos na práxis artística.

Je savais que c'était un artiste, um sculpteur, j'étais certaine que c'était um type très bien, Il avait um peu de ventre, portait um immense chapeau, une belle cravate Lavallière et, comble de richesse, ne sortait jamais sa canne à pommeau d'argent! Donc, ne sachant où aller, jê me rends chez lui et, le couer battant, je lui propose de poser nue ${ }^{13}$ (KIKI, 2003, p77).

Kiki de Montparnasse participava do cotidiano dos artistas, frequentando seus ateliês, acompanhando-os em suas vendas, em suas criações e discussões. Teve inclusive relacionamentos com alguns deles, cujo mais conhecido foi o com Man Ray, entre os anos de 1922-1929, período esse que coincide com o esplendor de Montparnasse e do próprio surrealismo, vale lembrar ${ }^{14}$. Foi companheira de viagem de Cocteau, de Tzara, de Picasso, de Picabia, de Aragon e de Man Ray. Há uma descrição no prefácio muito notória sobre Kiki:

ela era maravilhosa de se ver, sendo seu rosto naturalmente bonito, ela o havia convertido em obra de arte, tinha um corpo prodigiosamente belo e uma voz agradável. Kiki foi sem dúvida a rainha desse bairro de artista, sonho e destino de milhões de pessoas nos anos 20, e chegou a simbolizar tudo que oferecia Montparnasse (HEMINGWAY, 1929, p.17).

Esse grupo de amigos a seguia em bares e a assistia cantar em cabarés como o Le Jockey, Le Bouef sur Le Toit e por diversos cantos que formavam uma espécie de oasis que ocasionava a possibilidade de surgimento de muitas vertentes cujas individualidades criativas souberam gozar. Com boas doses de diversão e produção, a colônia artística formada, que entendia aquele contexto como cosmopolita, produzia o Dadaísmo e Surrealismo franceses.

12 Uma história em quadrinhos biográfico que leva por título Kiki de Montparnasse, ambientado na França do século XX que expõe cronologicamente em capítulos as experiências e os lugares frequentados por Kiki de maneira descritiva e fortemente documentado. Além de ser uma fonte fidedigna da vida de Kiki, a obra traz um foco artístico na Escola de Paris no período do entreguerras. O livro foi publicado pelo selo Galera da Editora Record em 2010 no Brasil.

13 Em português: "Eu sabia que ele era um artista, um escultor, eu tinha certeza de que ele era um cara muito bom, ele tinha um pouco de barriga, usava um enorme chapéu, uma linda gravata de Lavallière e, no auge da riqueza, nunca saía sem sua bengala com um pomo de prata! Então, sem saber para onde ir, vou para casa dele e, com o coração a mil, proponho ficar nua" (tradução minha).

14 Man Ray conhece Kiki logo nos primeiros anos que chega a Paris. Ela passa rapidamente a ser sua mais notável musa surrealista, experimentando com ela uma série de técnicas para sua fotografia vanguardista. Cf. "Las dos caras de Kiki. Retratos de una musa de Montparnasse", Congreso Internacional Imagen Apariencia, (2008); Wendy A. Grossman \& Steven Manford, Une icône démasquée : Noire et blanchede Man Ray, In: American Art 20, n² 2, verão de 2006, p. $134-147$. 


\section{Conclusão}

A presença feminina na esteira da produção artística em inúmeras ocasiões foi e é - velada ou eclipsada em seu papel como agente do desenvolvimento da criação artística, restando, no mais das vezes, um papel secundário de "companheiras" ou "musas" de artistas. A investigação sobre essas "companheiras" vem adquirindo um protagonismo cada vez maior no âmbito acadêmico: institutos, museus, exposições, centro culturais, associações, programas de graduação e pós-graduação, etc., organizam os mais diversos eventos para valorização, visibilidade e o empoderamento da mulher no mundo das artes, movimento que busca contestar o argumento de que a suposta escassez de figuras femininas artistas, ou influências femininas no campo, se daria em decorrência da falta de talento, de rigor e relevância ${ }^{15}$.

Mobilizar e desestabilizar o imáginário visual impregnado por idolatrias e fascinação que acessa ligeiramente ícones com nomes masculinos é imperativo além do mais por desvelar nomes e trajetórias dentro da História da Arte que foram subestimados ou ignorados, cuja presença feminina era maior, sobretudo nos períodos de revolução social no século XIX e XX, fração de tempo que conjuga a crescente aparição da mulher na esfera pública.

É também através dos movimentos sociais femininos e da transgressão de normas clássicas estéticas de imitação da natureza nos chamados "ismos" vanguardistas que, presenciamos nas artes, formas inovadoras de apresentação e representação da figura feminina no processo de criação, em pinturas, esculturas, fotografias, filmes e músicas com os quais nos ocupamos para falar de Kiki de Montparnasse.

Cabe enfatizar que muitas das obras que hoje sedimentam nossa memória visual ou nossas leituras não seriam o que são hoje se não tivessem as contribuições valiosas de musas ou "companheiras" de trabalho de artistas emblemáticos, mas cujos nomes foram borrados ao longo do caminho.

Sem um devido lugar no momento histórico atual, como tiveram em seu tempo publicamente e no meio artístico, essas presenças, na produção de seus amigos, confidentes, colegas e companheiros, estabelecem-se variavelmente equivocadamente na Crítica e História da Arte: em um lugar sem honra e mérito.

\section{Referências}

BENSTOCK, Shari. Women of the Left Bank: Paris, 1900- 1940. Londres: Virago, $1987,566 \mathrm{p}$.

BUTLER, Judith P. Gender Trouble: Feminism and the Subversion of Identity. Londres: Routledge, 2006, 236 p.

\footnotetext{
15 Os casos notáveis são por demais extensos para que possam ser aqui resumidos. Sugiro apenas alguns pulverizados exemplos recentes globais e locais de esforços e projetos para trazer à tona essa temática e que correspondem a respostas concretas e positivas às proposições, indagações e críticas que se vem fazendo à relação entre gênero e arte : em 2009 o Musée National d'Art Moderne, mais conhecido como Centre Georges Pompidou, realizou uma exposição das obras de mulheres artistas presentes em sua coleção; em 2010, o MoMA de Nova lorque lançou o livro Modern Women (Butler e Schwartz, 2010), que se dedica ao levantamento, análise e compreensão das obras de mulheres artistas em sua coleção; em 2017, o Museu de Arte de São Paulo organizou a exposição "Guerrilla Girls: gráfica, 1985-2017" que denuncia o desequilíbrio entre mulheres e homens nos cenários da arte moderna e da arte contemporânea.
} 
DALTON, S. Engendering the Republic of Letters: Reconnecting Public and Private Spheres in Eighteenth-Century Europe. Montreal-Kingston: McGill-Queen's University Press, 2003, 206 p.

ELLIOTT, Bridget. New and Not so ‘New Women' on the London Stage: Aubrey Beardsley's Yellow Book Images of Mrs. Patrick Campbell and Réjane. Victorian Studies: 1987, p.33-57.

GAMMEL, I. (ed.) Confessional Politics: Women's Sexual Self-Representation in Life Writing and Popular Media. Carbondale and Edwardsville: Southern Illinois University Press, 1999, 196 p.

GARB, T. Sisters of the Brush: Women's Artistic Culture in Late Nineteenth-Century Paris. New Haven: Yale University Press, 1994, 216 p.

GLASSCO, J. Memoirs of Montparnasse. New York Rewies Book: 2007, 296 p.

GROSSMAN, Wendy A.; MANFORD, Steven. Une icône démasquée: Noire et blanchede Man Ray, In: American Art 20, no 2, 2006, p. 134-147.

HABERMAS, J. Further reflections on the public sphere. In: Calhoun, Craig (Ed.). Habermas and the public sphere. Cambridge; Londres: MIT Press, 1992.

J. O discurso filosófico da modernidade: doze lições. São Paulo: Martins Fontes, 2002, $350 \mathrm{p}$.

HARRISON, C. et al. Modernidade e Modernismo: a pintura francesa no século XIX. São Paulo: Cosac Naify, 1998, 297 p.

HEMINGWAY, E. Introduction to Kiki of Montparnasse. In: Memoir's Souvenirs. 1929, p. 14-17.

KIKI DE MONTPARNASSE. Souvenirs Retrouvés. Paris: José Corti, 2003, 319 p.

KLÜVER, B.; MARTIN, J. Kiki's Paris: Artists and Lovers (1900-1930). Londres: Abrams, 1980, 264 p.

MAH, H. Phantasies of the Public Sphere: Rethinking the Habermas of Historians. In: The Journal of Modern History 72, março/2000, p.153-182.

MOULLGAARD, L. Kiki de Montparnasse. São Paulo: Martins Fontes, 1990, 354 p.

ROBERTS, M. L. Disruptive Acts, and Civilization without Sexes: Reconstructing Gender in Postwar France, 1917-1927. Chicago: Universidade de Chicago Press, 1994, $352 \mathrm{p}$. 
RODRIGUEZ S. C., Las dos caras de Kiki: retratos de una musa de Montparnasse. Congreso Internacional Imagen y Apariencia, 2009, s/ p.

SHOWALTER, Elaine. Sexual Anarchy: Gender and Culture at the Fin de Siècle. Nova York: Penguin Books, 1990, 242 p. 